\title{
Erratum to: Al-Si Alloys: Automotive, Aeronautical, and Aerospace Applications
}

\author{
Francisco C. Robles Hernandez, Jose Martin Herrera Ramírez, \\ and Robert Mackay
}

\section{Erratum to:}

F.C. Robles Hernandez et al., Al-Si Alloys: Automotive, Aeronautical, and Aerospace Applications, DOI 10.1007/978-3-319-58380-8

The original print and online versions of this book was inadvertently published with an uncorrected reference list and also the spelling of the (Dr. Robles Hernandez') name was incorrect. The name should read as follows:

Francisco C. Robles Hernandez

\footnotetext{
The updated online version of this book can be found at https://doi.org/10.1007/978-3-319-58380-8
}

\author{
Francisco C. Robles Hernandez ( $\square)$ \\ College of Technology \\ University of Houston \\ Houston, Texas, USA \\ e-mail: fcrobles@central.uh.edu \\ Jose Martin Herrera Ramírez \\ Centro de Investigación en Materiales \\ Avanzados \\ Chihuahua, Mexico \\ e-mail: martin.herrera@cimav.edu.mx \\ Robert Mackay \\ Metallurgical \& Heat Treatment \\ Nemak US/Canada Business Unit \\ Windsor, Ontario, Canada \\ e-mail: Robert.Mackay@Nemak.com
}

